\title{
Finite element analysis of the thermomechanical behavior of metal matrix composites (MMC)
}

\author{
Zaoui Bouchra, Baghdadi Mohammed, Serier Boualem, Belhouari Mohammed \\ University of Djillali Liabes, Laboratory of Mechanics Physics of Materials (LMPM Laboratory), Sidi Bel Abbes, Algeria. \\ zaouibouchra55@yahoo.com,mobbagh0@gmail.com,boualems@yahoo.fr,belbouari@yahoo.com
}

\begin{abstract}
In this work the finite element method (FEM) was used to analyze the mechanical behavior of the composite materials subjected to the mechanical loading. This behavior is studied in terms of stress intensity factor variation as a function of the applied stress intensity. The residual stresses induced in the composites, during the elaboration of these composites are taken into consideration in this study. The superimposition of these types of stresses (residuals and commissioning) is simulated here by thermomechanical stresses. The results obtained show that in the vicinity very close to the fibermatrix interface and under the effect of this loading type, the matrix cracks propagate in modes I, II and III, and far from the interface, in mode I. The propagation kinetics is slowed down by the interface-crack interaction.

The effects of the crack size, the orientation and propagation of the crack, commissioning stresses, the elaboration temperature, fiber physical properties, matrix stiffness and thermomechanical stresses have been highlighted in this work.
\end{abstract}

KEYwORDS. Composites; Crack growth; FEM; Residual stresses; Stress Intensity Factor (SIF); Interface.

\section{open Access}

Citation: Zaoui, B., Baghdadi, M., Serier, B. Belhouari, B., Finite Element Analysis of the thermomechanical Behavior of metal matrix composites (MMC), 51 (2020) 174-188.

Received: 15.09.2019

Accepted: 22.11 .2019

Published: 01.01.2020

Copyright: (C) 2019 This is an open access article under the terms of the CC-BY 4.0, which permits unrestricted use, distribution, and reproduction in any medium, provided the original author and source are credited.

\section{INTRODUCTION}

$\mathrm{T}$ he composite materials are assembled materials, usually two immiscible components whose mechanical properties complement each to other. This design makes it possible to improve the mechanical characteristics (rigidity, lightness, corrosion, etc.) and to cope with increasingly stringent commissioning conditions, to cope with the conditions of commissioning more and more severe. This explains, the increasing use of the composite material in the industrial sector and especially in the aeronautic domain, aerospace domain, maritime domain, automotive domain and civil engineering domain etc. Nevertheless, these materials have a major disadvantage. In fact, during the elaboration process, a residual stress develops during the cooling of the elaboration temperature to ambient temperature. These stresses are generally due to the difference in stiffness materials and the thermal expansion coefficient, between the reinforcing material (fiber) and the matrix, the main constituents of composite materials. 
This difference weakens the adhesion between these two components and therefore promotes the initiation and propagation of fatigue microcracks. In fact, the fatigue sub-interfacial microcracks can be initiated in one of these two constituents, and their propagation leads to the ruin of the composite. The initiation of interface cracks may be due either to a poor mechanical attachment, or to the existence of internal shear stresses at the reinforcement-matrix interface. The level of these stresses and the energy of fiber-matrix adhesion, condition the composite rupture behavior. Added to commissioning stresses, these stresses (residual stresses) can be fatal for composites.

Several works have been devoted to the analysis of the composite rupture behavior. Thus, Hahn Chooa and al [1], have shown that, in the case of $\mathrm{Ni}-\mathrm{Al}$ metal matrix reinforced by unidirectionally $\mathrm{Al}_{2} \mathrm{O}_{3}$ alumina fibers, the relaxation of the residual stress, induced during the cooling or heating of the material, depends on the elastic or plastic properties, creep and the volume fraction of the fibers. Abou Msallem [2], based on thermomechanical and thermokinetic models, they have evaluated the residual stresses using the finite element method (FEM), and they have used also, the elastic limit of the resin (Matrix) as a criterion for the residual stresses presence. An experimental approach based on the peel-layer method makes it possible to deduce these residual stresses by measuring the moments and the induced curvatures, the residual stresses through the thickness estimated by this method are compared with those calculated from a thermoelastic model and a variational approach. Sellam and al [3], using the finite element method (FEM), they have analyzed the crack growth and their interaction with the defects. They show that, the propagation in modes I and II in the composites depends on the cracks location and the defects nature. Using the same method (FEM), Metehri and al [4] have shown that the level and distribution of residual stresses, in polymer matrices, are closely related to the fiber-matrix, fiber-fiber and fiber-interphase interaction. Boutabout and al [5] they analyzed numerically also, by the finite element method (FEM), the residual stresses developed in the copper-alumina and zirconia-alumina composite materials, they showed that these stresses are closely related to the gap between thermal expansion coefficients of these two constituents. Put the interface in shear. Mecirdi and al [6] using the finite element method (FEM) have highlighted the areas, exposed to the damage risk by a residual stress, developed in the composite which consists of soda-lime matrix and Sic fiber. Wang and al [7] have shown that the extended finite element method (XFEM), is an effective modeling technique for analyzing the initiation and propagation of a crack in composites. A method for evaluating the initial and progressive failure of composite laminates was proposed by Chi-Seung and al [8], based on the damage criterion and that of Puck, respectively. These authors used the Puck damage criterion to analyze the crack initiation and propagation in the fiber and the matrix. This latter determines the predominant mode of composite failure, they also show that the presence of defects in the crack propagation direction accelerates its instability. Węglewski and al [9], they analyzed experimentally, by neutron diffraction and numerically by the finite element method (FEM), the effect of alumina particle size $\left(\mathrm{Al}_{2} \mathrm{O}_{3}\right)$ on the level of the residual stresses generated during the processing cooling of the temperature, by sintering the metal matrix composite (chromium) at ambient temperature after cooling the elaboration temperature, This study allowed the development of numerical model of microcracking, induced by the residual stresses allowing the prediction of the effective Young modulus of the damaged composite. Prabha and Sirinivasan [10], using the stresses generated in the fiber and matrix, from direct tests on these two individual materials, have analyzed the degradation of the fiber and the matrix separately, they show that the damage phenomenon is different in these two constituents. Jin and al [11] have shown that, the delamination leads to both, a drop in macroscopic elastic stiffness and the mechanical strength of composites, these authors also analyzed the effect of the inclusion size on the macroscopic behavior of composites, they conclude that the inclusions of important size minimize the risk of interface disbanding and reduce the damage threshold. Safarabadi [12], analyzed the factors responsible for the formation of the residual stresses in composites and their effects on the fiber and matrix properties, this author presented, in this study, the analytical, numerical and experimental methods for the prediction of thermal residual stresses. Mecirdi and al [13], have shown, using the finite element method (FEM), that the behavior of the matrix cracks depends on the fiber volume fraction, the fiber-matrix interaction, the crack-inclusion interactions, microcavity and interface cracks. Yi Zeng and al [14], used the finite element analysis, they showed that the presence of carbide in the C/C composites leads to a significant increase in residual stresses in the $\mathrm{PyC}$ near the carbide, which explains why this compound could modify the distribution and the level of these stresses in these composites. Zhenyi and al [15], proposed a multiscale model allowing the prediction of residual stresses developed during the process of hardening (polymerization) of the composites and the correlation of the residual stresses at the microscopic and macroscopic scale. they showed that, there is too great gap in the calculation of micro-residual stresses by introducing the multiscale model effect. Nelson and al [16] based on a simplified approach to residual stresses modeling in composites, they developed a model (modeling), the experimental results obtained on bimaterial type composites were used to validate the modeling, they conclude that the experimental results are in very good agreement with those obtained from the simulation approach. Zhang and al [17] taking into account oriented curved fibers and the rule of change of fiber angles and determining the residual stresses using abaqus, have proposed a mathematical model of stratified composites with variable rigidity for the residual stresses 
prediction induced during the polymerization process, they showed that the residual stresses induced in composites with variable stiffness are reduced by increasing the final angle of the fiber path during the hardening process. Kati and al [18], using $\mathrm{X}$-ray diffraction (XRD), they analyzed the residual stresses induced in biphasic composite types $\mathrm{Ce}_{9} \mathrm{GdO}_{1-\mathrm{b}^{-}}$ $\mathrm{La}_{6} \mathrm{Sr}_{4} \mathrm{Co}_{2} \mathrm{Fe}_{8} \mathrm{O}_{3-6}$ (GDC-LSCF) obtained by sintering at $1250{ }^{\circ} \mathrm{C}$ and used for the manufacture of oxygen transport membranes, they showed that theses stresses put on compression the GDC and in tension the LSCF. The scanning electron microscopy has shown that these two compounds crystallize in cubic and rhombohedral spatial groups respectively.

This work fits into this context and aims to highlight the residual stresses and their effect on the performance of metal matrix composites. This latter is analyzed, in terms of the stress intensity factor variation (SIF) in opening modes (mode I) and in shear modes (modes II and III). The majority of the latest scientific work realized until now, do not take into account the residual stresses, induced during the elaboration of the composite strongly localized in the fiber-matrix interface vicinity, in the prediction of the composite damage. The originality of this work lies therefore in the prediction of the rupture behavior of the composite materials subjected to the superposition of these residual stresses to the commissioning stresses. On the other parts, a matrix crack initiated perpendicular to the tensile forces propagates in mixed mode I, II and III. The Abaqus calculation code, based on the finite element method, was used to achieve this objective. For this purpose, a three-dimensional numerical model has been developed.

\section{GEOMETRIC MODEL DEVELOPED IN THIS WORK}

7 he finite element method (FEM) was used to analyze the matrix cracks behavior in composite materiel subjected to mechanical stresses, thermal stresses and thermomechanical stresses. This last (thermomechanical stresses) simulates the superposition of the residual stresses to those of commissioning stresses. To do this, the Abaqus software version 6.11 [19] was used. For this purpose, a three-dimensional model has been developed, this last regroup a metal matrix of parallelepiped shape, having two capillaries, along its main axis, in which two cylindrical fibers are inserted (Fig. 1). The latter constitutes an elementary cell of a unidirectional composite. A crack of size "a", initiated in the matrix perpendicular to the main axis of the fiber, and then oriented at an angle " $\Theta$ ", relative to the longitudinal axis of the fiber (Fig. 1), this crack propagates to the reinforcing material. This structure is subjected to uniaxial tension stresses (Fig. 2a). Due to the symmetry of the developed model, only half of it has been taken into consideration. For this purpose, the imposed boundary conditions are: $\mathrm{U}_{\mathrm{Y}}=\mathrm{U}_{\mathrm{RX}}=\mathrm{U}_{\mathrm{RZ}}=0$ (condition of symmetry relative to y) (Fig. 2a).

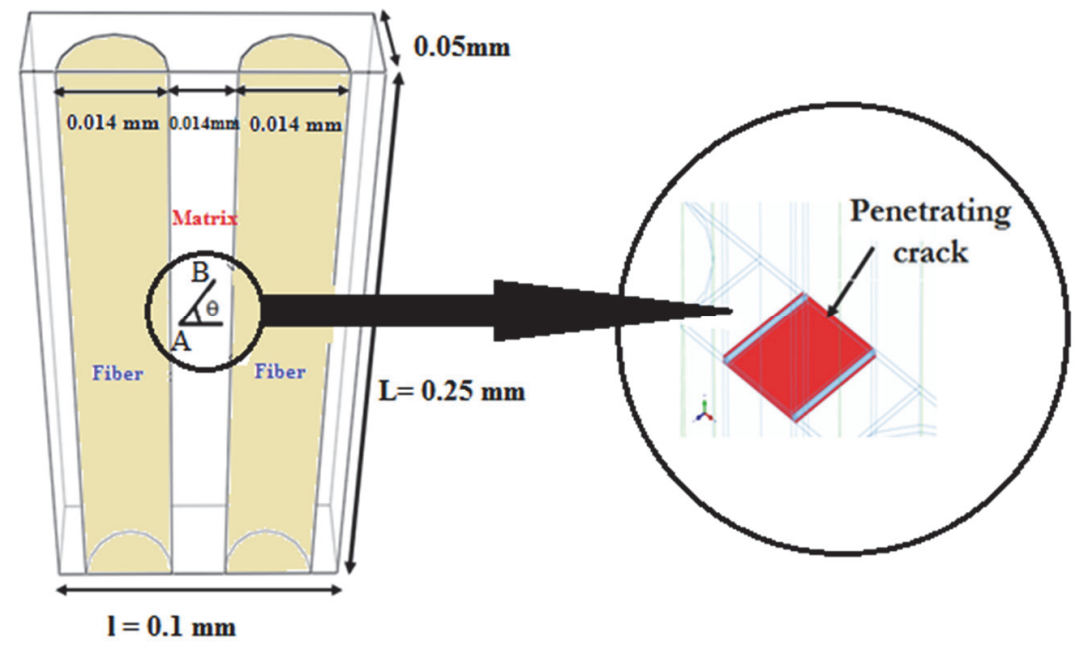

Figure 1: The analyzed structure.

The three-dimensional model developed in this work was meshed globally using the elements of the type C3D8. (An 8node linear brick) (Fig. 2). To obtain a correct representation of the displacement field near the crack, the elements called singular are used (elements type Barssoum.), as suggested by the Abaqus software documentation. The type of singularity $1 / \mathrm{V}_{\mathrm{r}}$, for the stress fields are obtained by moving all the intermediate nodes of the elements around the crack heads to a 
quarter of a distance from the nodes belonging to the considered crack head. The mesh of the crack head was exclusively refined using this special type element (Fig. 2).

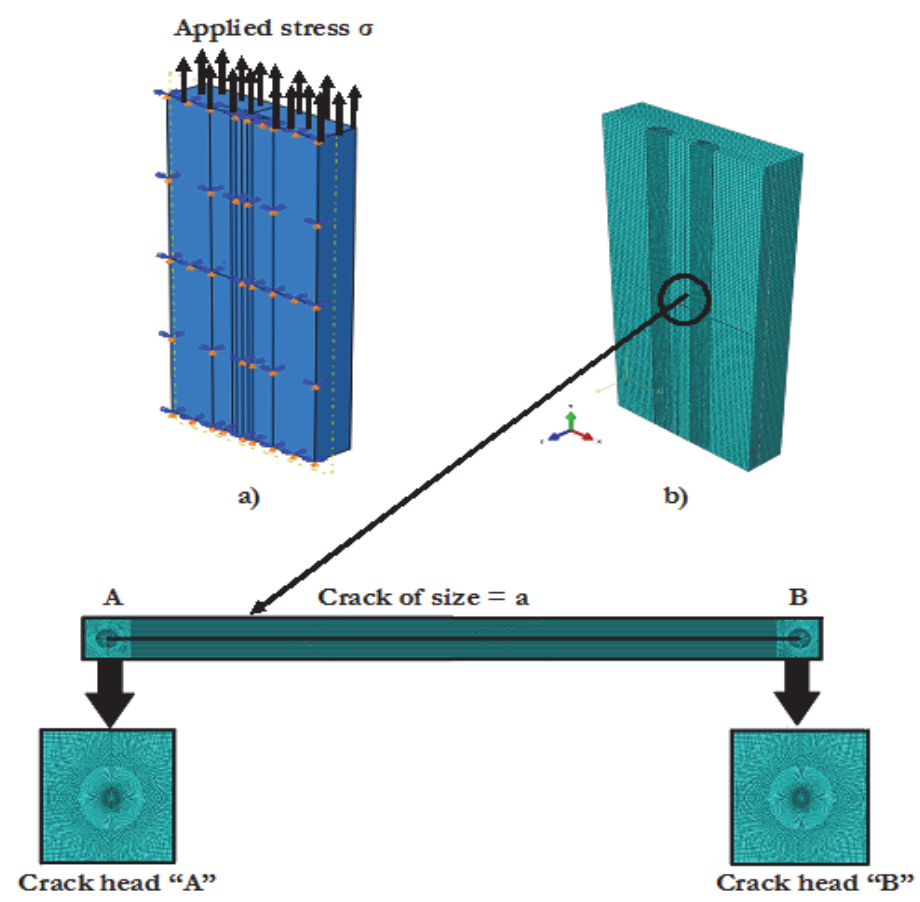

c)

Figure 2: The finite elements model. a) Boundary conditions, b) Total mesh of structure, c) Refined mesh in the vicinity of the crack heads.

The side sizes of an element, far from the crack and in the crack vicinity, were represented in Tab. 1, these sizes and types of mesh, remains the same for all the simulations in this study, to avoid any influence of the mesh on the results.

\begin{tabular}{ccc}
\hline $\begin{array}{c}\text { The different components } \\
\text { of the analysed structure }\end{array}$ & Numbers of elements & Sizes of elements \\
metal matrix & 115200 & $0.001 \mathrm{~mm}$ \\
Crack front & 280 & $0.001 \mathrm{~mm}$ \\
Fibres & 104000 & $0.001 \mathrm{~mm}$ \\
& 219480 & $0.001 \mathrm{~mm}$ \\
\hline
\end{tabular}

Table 1: Numbers and sizes of the mesh elements.

Reinforcement materials are assumed to be elastic linear isotropic and the matrix is elastic linear isotropic also, whose mechanical and physical characteristics are grouped in Tab. 2. The criterion to predict the angle at which a pre-existing crack is propagate used in this work, is the maximum energy release rate criterion (MERR), it is based on the work of Hussain et al. (1974), Nuismer (1975), Palaniswamy and Knauss (1978), as well as Wu (1978). This criterion proposed in abaqus documentation. 


\begin{tabular}{|c|c|c|c|}
\hline Materials & $\begin{array}{l}\text { Young modulus } \\
\qquad \mathrm{E}(\mathrm{MPa})\end{array}$ & $\begin{array}{l}\text { Poisson } \\
\text { Coefficient } v\end{array}$ & $\begin{array}{l}\text { Expansion } \\
\text { thermal Coefficient } \alpha\left(10^{-6} \mathrm{~K}^{-1}\right)\end{array}$ \\
\hline Nickel (Ni) & 207000 & 0.31 & 13 \\
\hline silicon carbide $(\mathrm{SiC})$ & 450000 & 0.17 & 2.8 \\
\hline silver (Ag) & 76000 & 0.37 & 20 \\
\hline Bromine $(\mathrm{Br})$ & 400000 & 0.21 & 4.5 \\
\hline Copper $(\mathrm{Cu})$ & 124000 & 0.33 & 17 \\
\hline Alumina $\left(\mathrm{Al}_{2} \mathrm{O}_{3}\right)$ & 350000 & 0.25 & 8 \\
\hline
\end{tabular}

Table 2: Mechanical and physical properties of the constituents of the composites used (Serier [20]).

\section{RESULTS AND DISCUSSION}

\section{Effect of the elaboration temperature intensity}

omposites are elaborated at relatively high temperatures. These temperatures promote mechanical bonding between the fiber and the matrix and ensure good adhesion between these two constituents. The adhesion energy, conditioning the fiber-matrix charge transfer, is all the stronger as the elaboration temperature is higher. Nevertheless, this last (elaboration temperature) induces in these two components residual stresses in the vicinity very close of the fiber-matrix interface due to the difference between the thermal expansion coefficient of the fiber and the matrix. In fact, at the elaboration temperature of the composite, the metal matrix retracts much more than the ceramic fiber; this phenomenon resulting shear stresses at the matrix-fiber interface due to the equalization of the elastic deformations of the matrix and the fiber:

$$
\varepsilon_{m}=\alpha_{m}\left(T_{0}-T\right) \text { and } \varepsilon_{f}=\alpha_{f}\left(T_{0}-T\right)
$$

$\alpha_{\mathrm{m}}$ and $\alpha_{\mathrm{c}}$ are the thermal expansion coefficients of the matrix and the fiber respectively. With $\Delta \alpha=\alpha_{\mathrm{m}}-\alpha_{\mathrm{c}}$.

$\Delta \mathrm{T}=\left(\mathrm{T}-\mathrm{T}_{0}\right)$ is the temperature gap from the reference temperature. These internal stresses are a function not only of the gap between the thermal expansion coefficients of the matrix and the fiber, of the gap between the temperature at which the thermoelastic deformation disappears and the elaboration temperature but also of the elastic modulus of the two constituents (fiber and matrix).

For a long-fiber unidirectional composite, in the axial middle phase matrix, the thermal residual stresses Induced during the elaboration process of composite material $\left\langle\sigma^{\mathrm{Th}} 3\right\rangle_{\mathrm{m}}$, and in fiber, $\left\langle\sigma^{\mathrm{Th}}{ }_{33}\right\rangle_{\mathrm{f}}$, are expressed by (Withers and al [21]):

$$
\begin{aligned}
& <\sigma_{33}^{T h}>_{f}=-\frac{f_{m} E_{m} E_{f} \Delta \alpha \Delta T}{f_{f} E_{f}+f_{m} E_{m}} \\
& <\sigma_{33}^{T h}>_{m}=\frac{f_{f} E_{m} E_{f} \Delta \alpha \Delta T}{f_{f} E_{f}+f_{m} E_{m}}
\end{aligned}
$$

$f_{m}$ and $f_{f}$ are the volume fractions of the matrix and the fiber respectively, $E_{m}$ and $E_{f}$ their respective elastic modulus. In some cases, the residual stresses of thermal origin are critical to facilitate the transfer of stresses from one phase to another. In fact, in a composite material of long fiber, the clamping of the fibers by the matrix during its cooling of the elaboration temperature, determines the level of the frictional stress necessary to pull the fiber out of the matrix. For a long, insulated fiber in a unidirectional metal matrix composite (MMC), the radial residual stress of matrix-fiber clamping is expressed by (Withers and al [21]): 


$$
\sigma_{N}^{T b}=\frac{E_{m} E_{f} \Delta \alpha \Delta T}{\left(1+v_{m}\right) E_{f}+\left(1-v_{f}\right) E_{m}}
$$

$\nu_{\mathrm{m}}$ and $\nu_{\mathrm{f}}$ are the Poisson coefficients of the matrix and the fiber respectively.

This component, of the residual stresses, reinforces the adhesion between the matrix and the fiber and disadvantages the delamination of the composites. Generally, the metal matrix composites are composed of matrices whose a thermal expansion coefficient is much higher than that of the fiber, which generates more intense residual stresses. The highly localized residual stresses at the matrix-fiber interface can constitute a barrier for charge transfer, from the ductile metal matrix to the rigid fiber. On the other hand, added to the commissioning stresses, these stresses (residual stresses) can be responsible for the composites damage by initiation and propagation of fatigue cracks. These stresses are generated during the cooling of the elaboration temperature, initially high, to ambient temperature. According to the relations (1), (2) and (3), this temperature generates more intense residual stresses in unidirectional metal matrix composite (MMC). Therefore, the analysis of this temperature effect is of great use, in other words, is of great value for the performance of the CMM. To do this, we chose a nickel matrix composite "Ni" reinforced by unidirectional silicon carbide fibers "SiC" elaborated at given temperatures. To simulate the residual stress effect, a fatigue crack of size "a" is initiated in the matrix.

Far from the crack, under elastic residual stress effect, the fibers are axially in compression and the matrix in tension, as shown by Metahri and al [4].

The result obtained, clearly defined that, under the effect of these stresses and in the vicinity very close of the fiber-matrix interface, the matrix crack propagates in mixed modes I, II, and III (Fig. 3).It is these non-zero values of stress intensity factors obtained in the simulation in three modes that are characteristic of such growth. These ruptures criteria are all the more important as the composites are elaborated at high temperatures. The residual tensile stresses in the matrix act as a crack opening stresses. In mode I, the stress intensity factor values increase with the crack size and with the temperature, after then drop as the crack front, approach the interface (Fig. 3a). It is the crack-interface interaction that is responsible for the decreasing of the matrix crack propagation speed to the fiber. In fact, the interaction of strongly localized stress fields at the crack fronts and at the fiber-matrix interface leads to a reduction of the stress intensity factor in the mode I. For this purpose, in the vicinity very close of the fiber-matrix interface, the crack propagates essentially under the action of highly concentrated residual stresses at the interface. When the crack fronts crosses the interface, this parameter drops abruptly.

In the fiber, the residual stresses deal as compression stresses which act as closure stresses of the crack (Fig. 3a). The negative values of the stress intensity factor at the crack head are characteristic of this closure (Fig. 3a). This behavior clearly shows that the propagation of the matrix crack is being finally stopped by the fiber and whatever the elaboration temperature of the composite. The crack propagation, in modes II and III, intervenes only when the front of the matrix crack tends towards the interface $(\mathrm{a}=13 \mu \mathrm{m})$ and crossed the interface $(\mathrm{a}=15 \mu \mathrm{m})$ (Fig. $3 \mathrm{~b}$ and $3 \mathrm{c})$, beyond this size the crack propagates in the fiber is in pure mode I. The propagation kinetics is all the stronger as the composite is elaborated at high temperatures. This kinetics are defined in terms of stress intensity factor variation in shear modes (mode II and mode III) (Fig. 3b and 3c). Far from the fiber, no propagation in these two modes is observed, the stress intensity factors characteristic of these modes are of zero values (Fig. 3b and 3c). This behavior clearly illustrates that matrix crack initiated far from the interface propagates in pure opening mode (Mode I). Its development towards the fiber is done both, by shearing and by the opening of its lips. It is the residual stress, of tension in the matrix and the compression in the fiber that is responsible for such propagation. The results illustrated in Fig. 3 show that the propagation kinetics is even stronger than the composite is elaborated at high temperatures.

The crack propagation, in mode I, towards the fiber is broken by the compression residual stresses induced in this component. But, by penetrating the fiber, the crack propagates in mixed mode II and III by shearing of its lips (Fig. 3b and $3 \mathrm{c}$ ). This clearly illustrates that, under residual stress effect, the crack propagation mode in the matrix and in the fiber is different. It is the fiber-matrix interaction that is responsible for crack growth in shear modes (mode II and III).The results obtained in this part of the work show that under the residual stress effect, a crack, initiated in the matrix, propagates in pure mode I when its front is located relatively far from the interface with the fiber and in mixed modes I, II and III when his front approaches towards this interface. In the latter case, the crack propagates preferentially in the open mode (mode I). The very high values of stress intensity factors are characteristic of such predominance (Fig. 3a). The stress intensity factors at the heads of a matrix crack increase with the increase of its size and with the increase of the elaboration temperature of the composite; by penetrating the fiber (the crack penetrates the fiber), the matrix crack propagates only by shear of its lips in modes II and III. This elaboration temperature of the composite material is a determining parameter of the fiber-matrix adhesion; its increase leads to high adhesion energies between these two 
constituents of the composite and ensures a better resistance to the disbanding phenomenon. However, this temperature resulting a residual stress that can lead to the initiation and propagation of fatigue cracks and a premature damage to the composite.
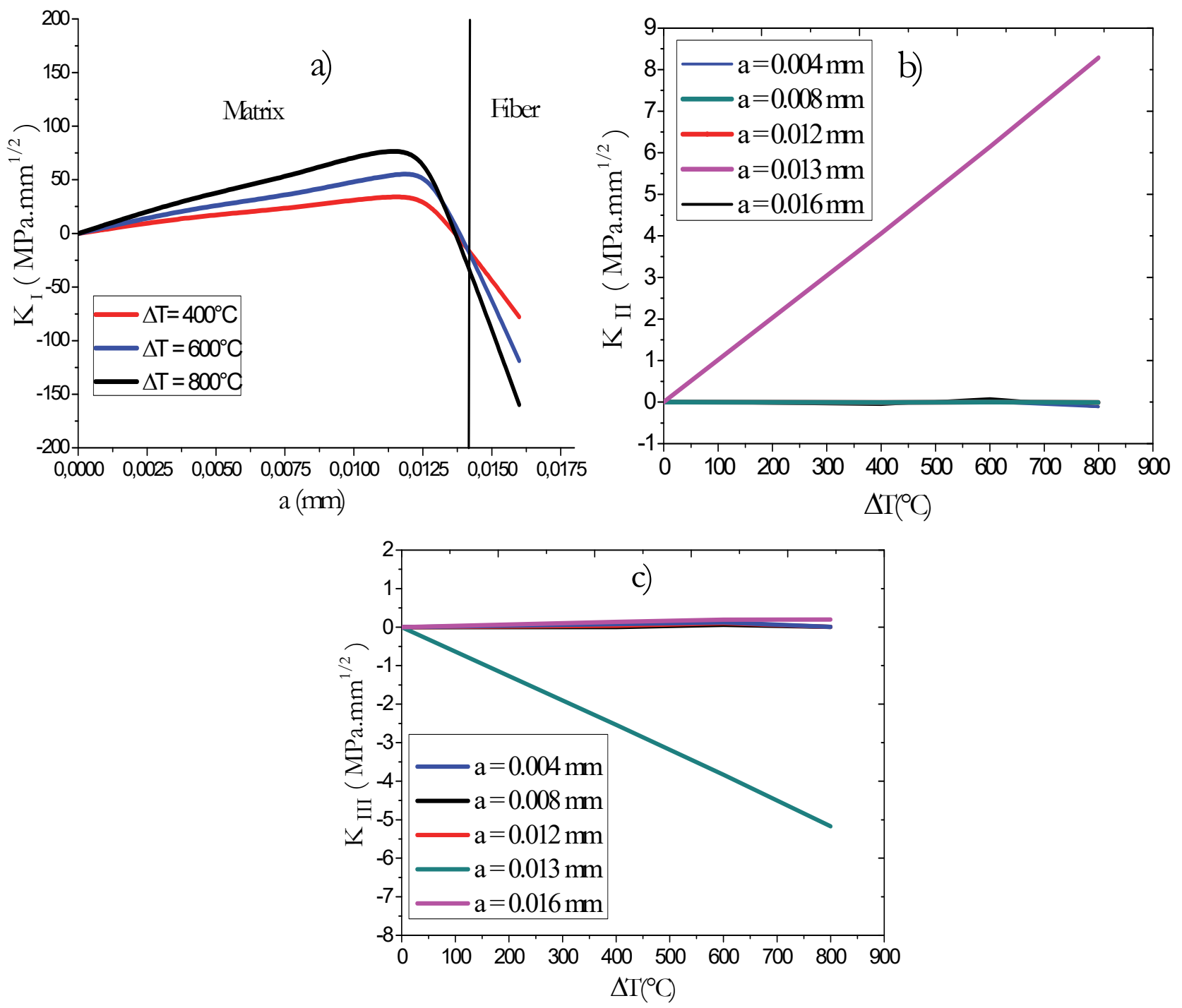

Figure 3: Variation of the stress intensity factors. a) in mode I, b) in mode II, c) in mode III, according to the elaboration temperature and the crack size.

\section{Effect of physical properties (thermal expansion coefficient)}

Relations (1), (2) and (3) show that for a given elaboration temperature, the difference between the thermal expansion coefficients of the two constituents of the composite (fiber and matrix) conditions the thermoelastic deformations and therefore the thermally induced stresses.

In this part, the effect of this physical parameter on the behavior of matrix cracks is analyzed. the results obtained in the Fig. 4 shown that the crack is all the more unstable in mode I, II and III when this difference, between the thermal expansion coefficients of the fiber and matrix, is more important, and that the predominant mode is the opening mode (Fig. 4). In fact, the values of the relative stress intensity factor in this mode (opening mode) are much higher than those corresponding to modes II and III (shearing modes). 


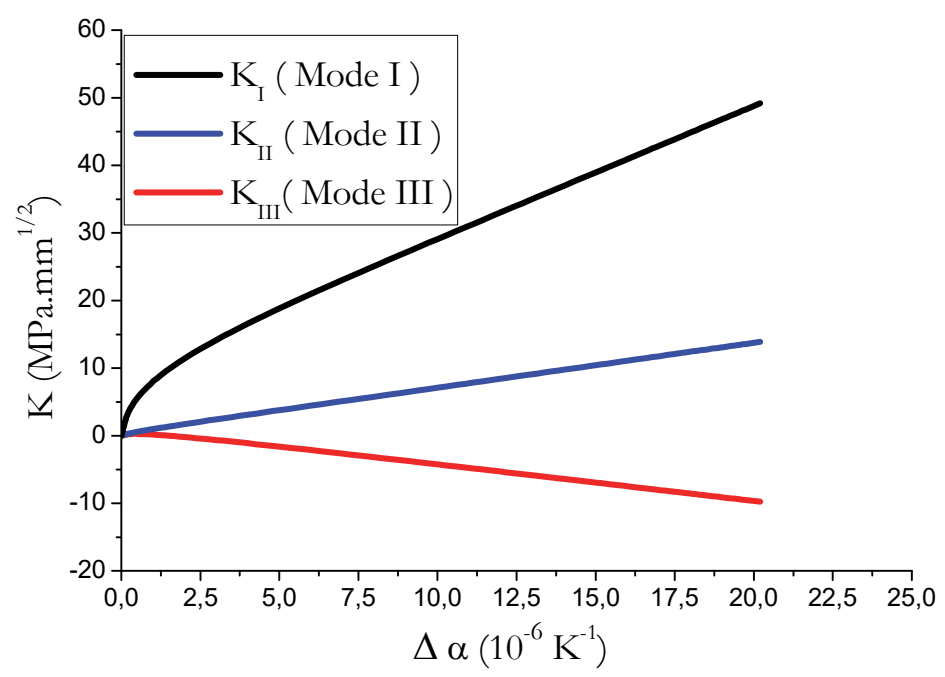

Figure 4: Variation of the stress intensity factor in modes I, II and III as a function of the gap of the thermal expansion coefficients of the matrix and the fiber: $\mathrm{a}=13 \mathrm{~mm}, \Delta \mathrm{T}=800^{\circ} \mathrm{C}$.
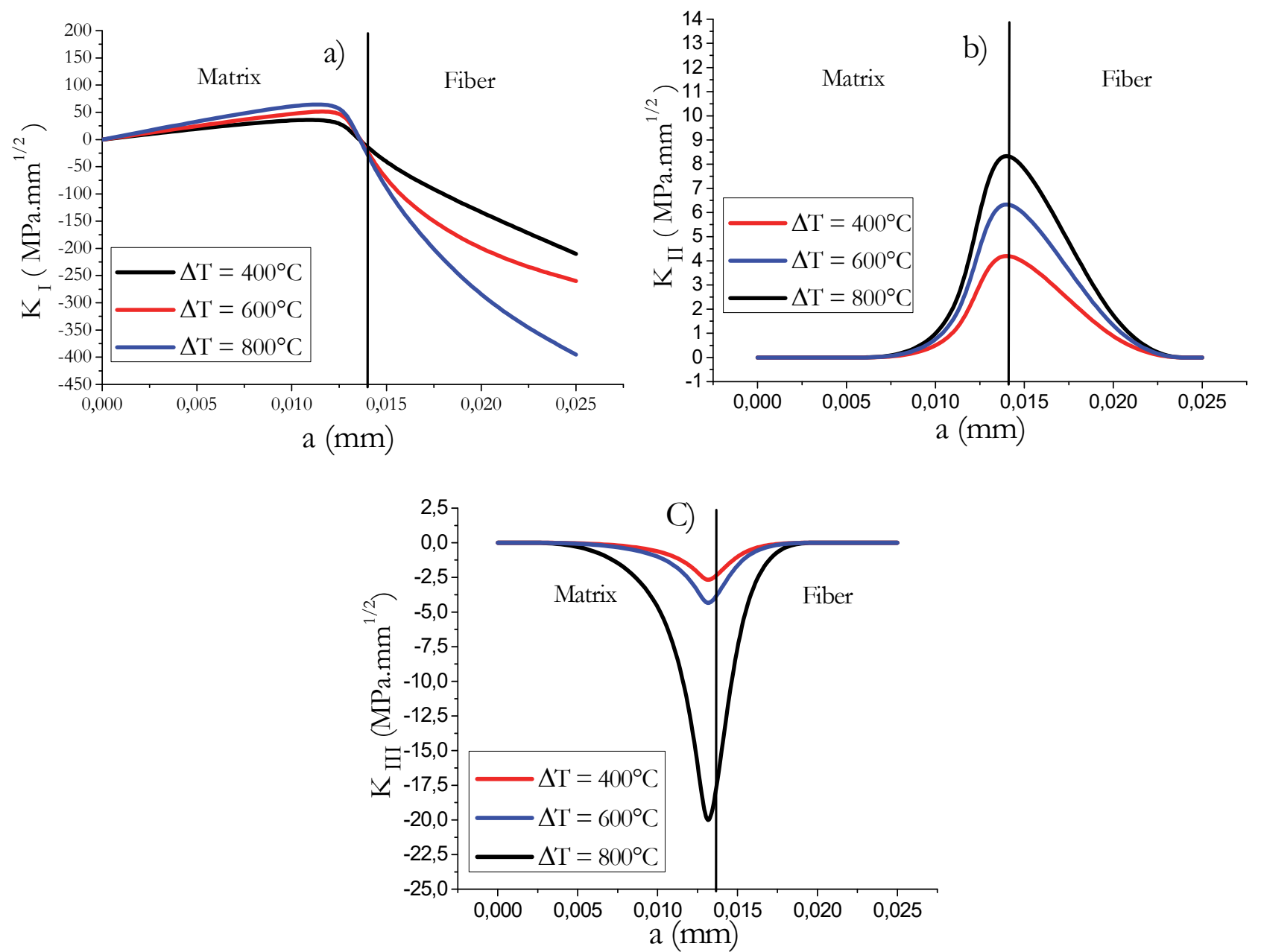

Figure 5: Effect of elaboration temperature of the composite on the matrix crack propagation. a) in mode I, b) in mode II, c) in mode III. 


\section{Effect of crack propagation (Crack sizes)}

Under the same simulation conditions of the previous study, the effect of the elaboration temperature of the composite, on the crack propagation, initiated in the matrix perpendicular to the main axis of the fiber, is analyzed. To do this, this crack propagates in the direction of the fiber (Fig. 5a, b and c).

The results obtained showed that, in mode I, the crack propagates only in the matrix. In this case, the stress intensity factor increases with the advance of the crack and with the increase of the elaboration temperature of the composite .The normal compressive residual stresses induced in the fiber cause the crack lips to close (Fig. 5a). The negative values of the stress intensity factor are characteristic of this closure. This crack does not propagates in mixed modes (mode II and III) only if its heads tends towards the interface (fiber-matrix interface), in this zone of the composite, the stress intensity factors values in these modes (mode II and III) reach their maximum values in the matrix and in the fiber (Fig. 5b and 5c).In other words, in this zone the crack propagates in mixed mode I, II and III; far from this zone, this crack develop in mode I in the matrix and in modes II and III in the fiber (Fig. 5a, b and c).The crack crossing the fiber by shearing its lips (modes II and III). The crack propagation kinetics in the composite is all the stronger as the fibers are jointly bonded to the matrix at high temperatures.
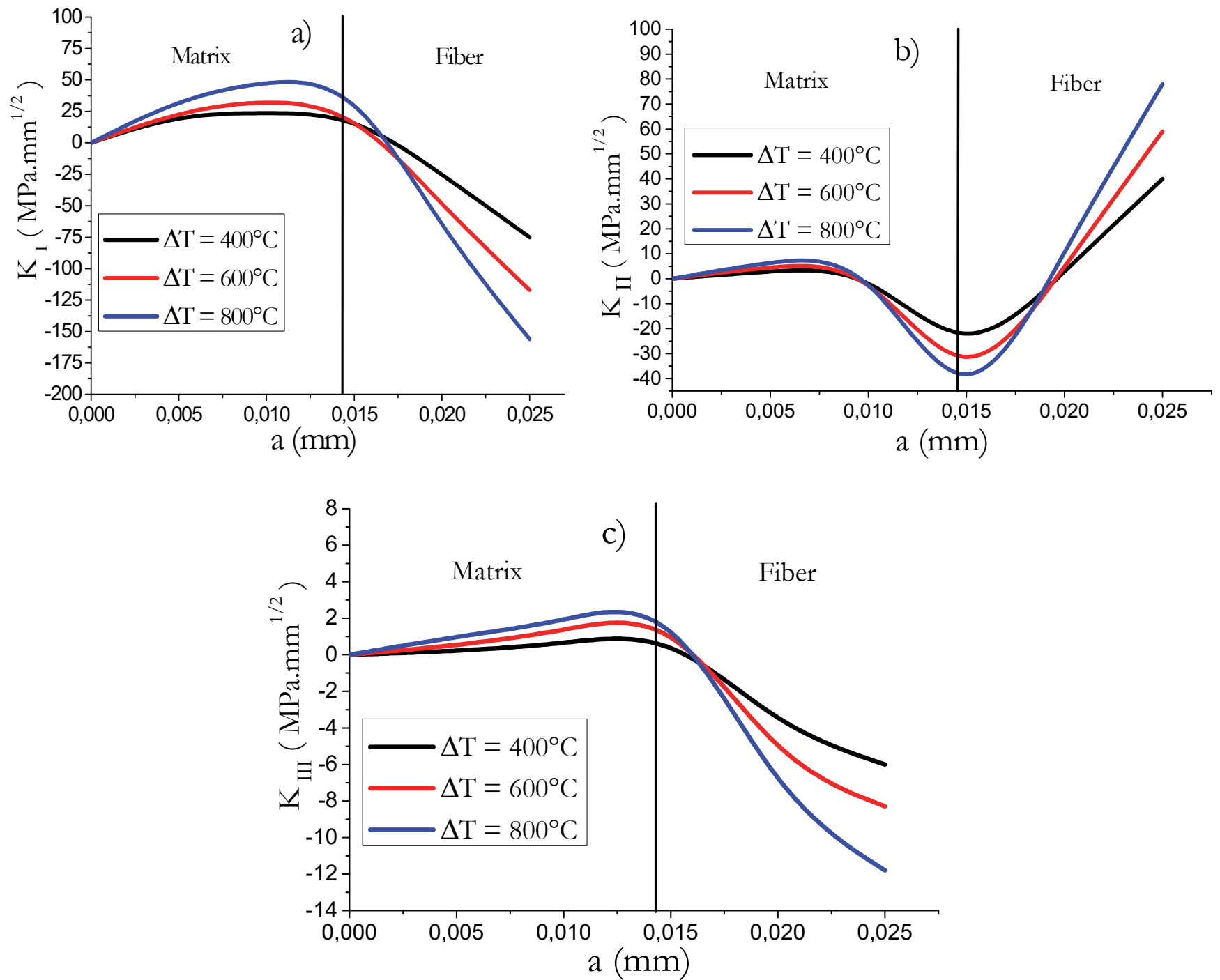

Figure 6: Variation of the stress intensity factor of the crack oriented at $45^{\circ}$ according to its size and the composite elaboration temperature. a) in mode I, b) in mode II, c) in mode III. 
Effect of crack orientation

The residual stresses of thermal origin effect on the behavior of a matrix crack, oriented at $45^{\circ}$ with respect to the longitudinal axis of the fiber, are analyzed in the following (Fig. 6). It is clearly shown that such a crack propagates in the matrix in mixed modes I, II and III and in the fiber in shear modes II and III (Fig. 6a, b and c). It is these non-zero values of the stress intensity factors in these three modes that are characteristic of this mode of growth. These rupture parameter values are all the more important as the $\mathrm{Ni} / \mathrm{SiC}$ composite is elaborated at relatively high temperatures. In opening mode and under the residual stress effect, the crack propagates only in the matrix; in the fiber these stresses act as closing stresses (Fig. 6a). This crack propagates by shearing of its lips (modes II and III) only when its front tends towards the fiber-matrix interface (Fig. 6b and 6c). The crack is all the more unstable as the composite is elaborated at high temperatures. Our results show that under the residual stress effect, the a matrix crack, oriented at $45^{\circ}$ propagates in the matrix, far from the interface with the fiber in pure mode I, and in the close vicinity of this interface in mixed modes I, II and III and in the fiber in mixed mode II and III. In mode I (Opening mode), the residual compression stresses induced in the fiber, act as crack closure stresses, which explains the negative values of the stress intensity factor.

\section{Effect of commissioning stresses (Applied stress intensity)}

Under the same simulation conditions, the behavior of the same structure as previously analyzed, is subject to commissioning stresses of varying amplitude, To put in the cracking conditions, the structure containing a matrix crack is solicited in uniaxial tension along the fiber (Fig. 1).Such a loading leads to a crack propagation in pure mode I (Opening mode) whose stress intensity factor increases with its advance towards the fiber, its threshold value is reached when its front approaches the fiber-matrix interface (Fig. 7).From this zone, this failure criterion drops, and then increases rapidly when this crack front crosses the interface and propagates in the fiber. It is the strong crack-interface interaction that is responsible for this drop. More severe commissioning conditions, defined by more intense applied stresses, lead to a high instability of the crack, defined by the high values of the stress intensity factor. It is clearly defined that the speed of cracks propagation is strongly slowed down in the matrix in the vicinity of the interface (Fig. 7).

Remember, that the values of the stress intensity factors in mode II and III are extremely low and will not be discussed here.

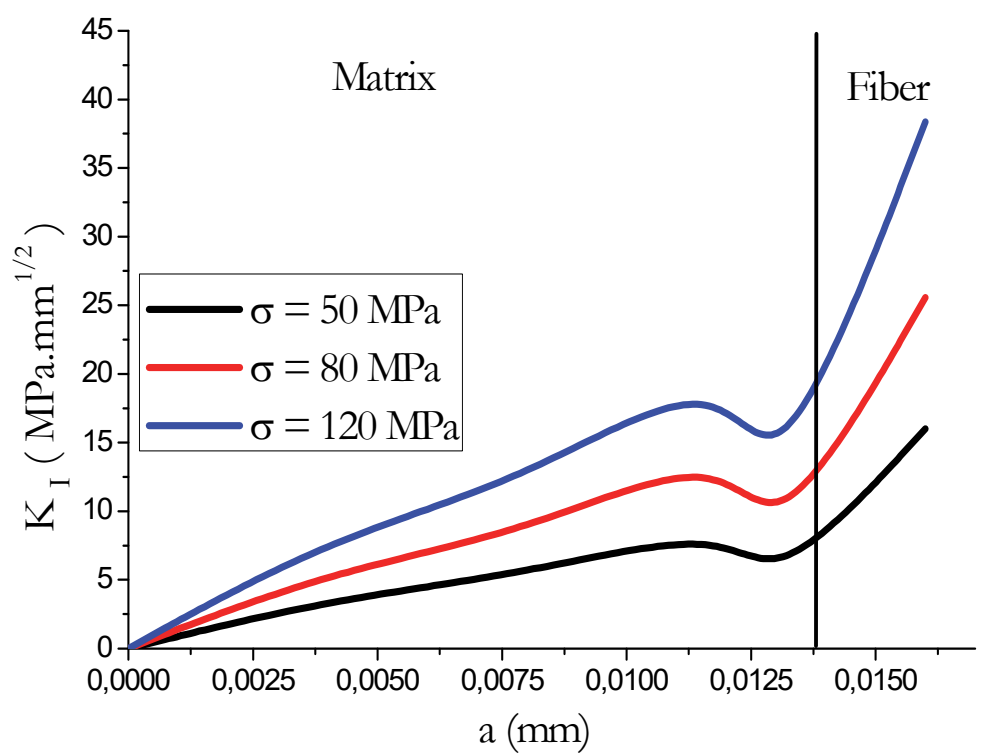

Figure 7: Variation of the stress intensity factor in mode I, as a function of the commissioning stresses intensities and the matrix crack size.

For a better analysis of the intensity of the commissioning stresses effect, the Fig. 8 shows, as a function of the crack size, the evolution of stress intensity factor in the mode I from the matrix to the fiber. In this case, the matrix crack, initiated perpendicular to the direction of traction, crosses the matrix, the interface and the fiber with a non-uniform propagation speed. In fact, it is slow in the matrix and accelerated in the fiber. Thus, the increase of the curve slope of the matrix 
towards the fiber is characteristic of this propagation kinetics variation of the crack. When the crack crosses the entire fiber and tends towards the second interface, this speed is again slowed down by the strong crack-interface interaction. This behavior is all the more marked as the commissioning stress is more intense.

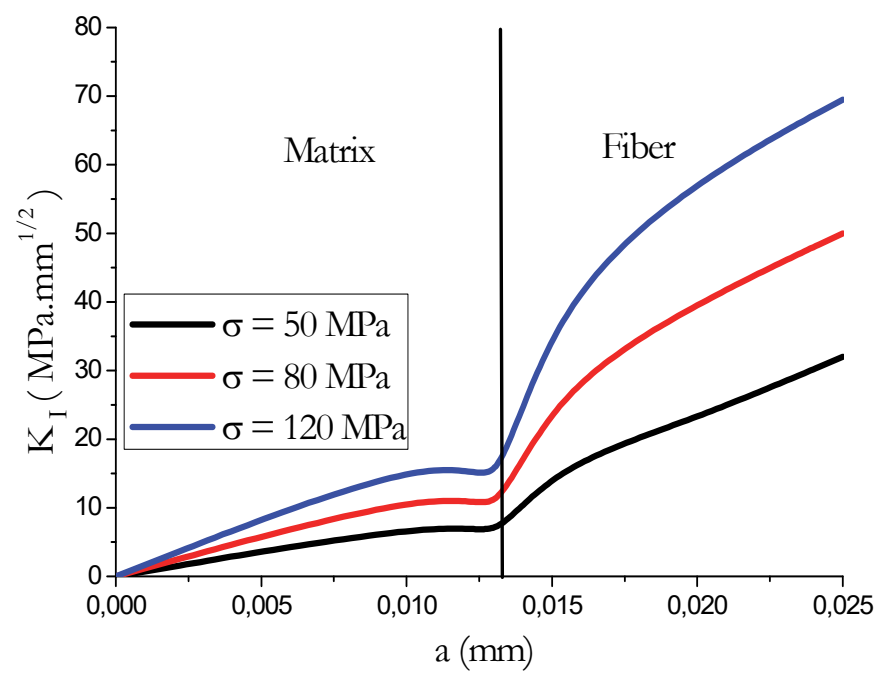

Figure 8: Effect of the commissioning stress intensities on matrix crack propagation in mode I.
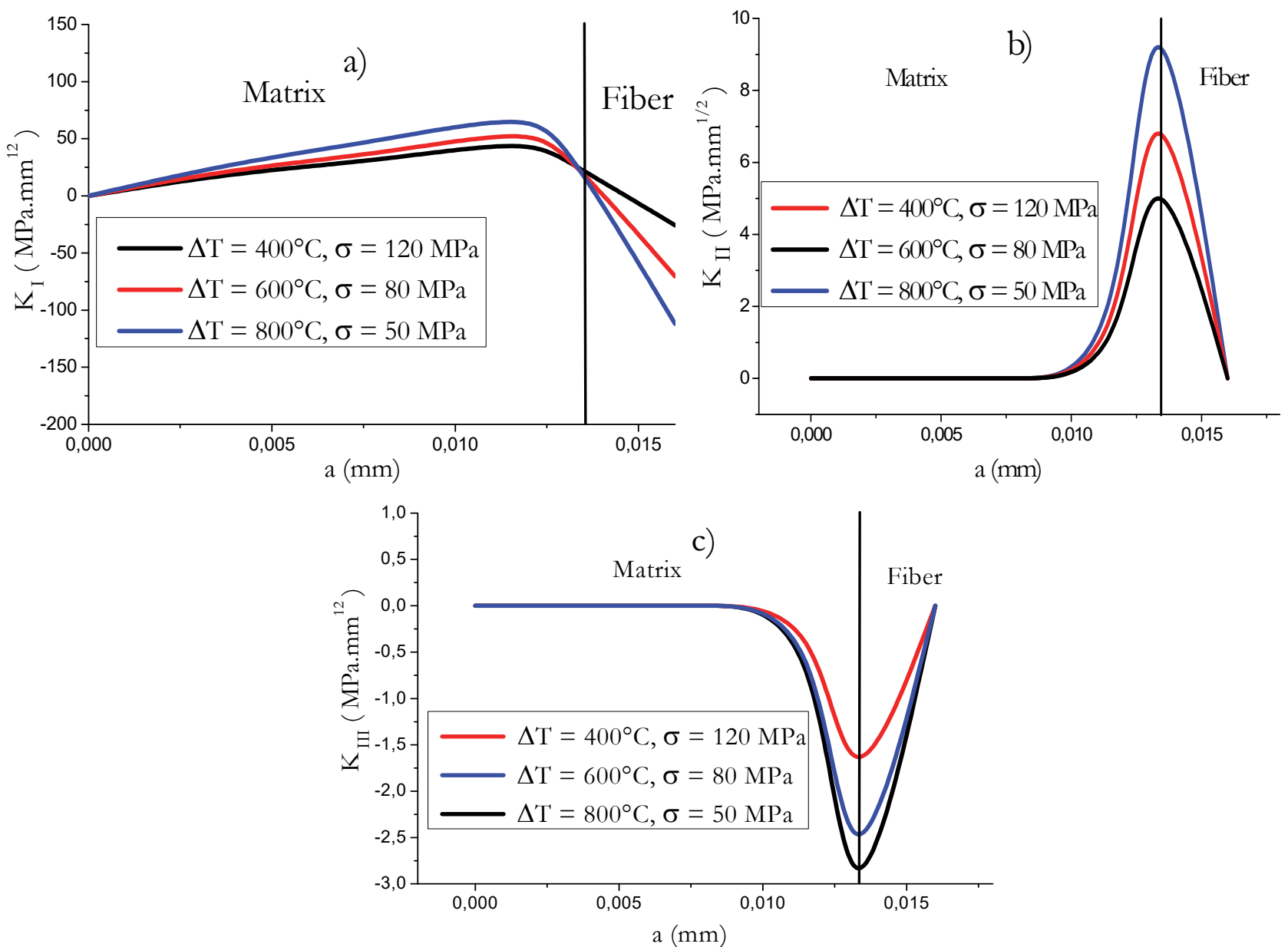

Figure 9: Variation of the stress intensity factor according to applied thermomechanical stresses intensities. a) in mode I, b) in mode II, c) in mode III. 
Effect of thermomechanical stresses

Thermomechanical stresses simulate, here, is the superposition of commissioning stresses and thermal residual stresses. This energy accumulation, in the case of composite materials, is largely responsible for their premature damage by initiation and propagation of fatigue cracks. For this purpose, the demonstration of the superposition effect on the behavior of a matrix crack is of great importance for the performance of metal matrix composites. To do this, the same conditions of solicitations and simulations as those used previously were retained. Under the superposition effect, the crack propagates in the matrix is of pure mode I (opening mode) and in the vicinity very close to interface, in mixed modes I, II and III and in the fiber in shear modes II and III (Fig. 9b and 9c).In mode I, in the fiber, the commissioning stresses of tension are retrenching from the residual stresses of compression, these last act like closing forces, this last (closing forces) is defined by the negative values of the stress intensity factor (Fig. 9a).In the matrix the commissioning stresses and the residual stresses are added, which makes the matrix vulnerable to damage by cracking. Under the thermomechanical stress effect, the matrix crack, penetrates and propagates in the fiber by shearing its lips (Fig. $9 \mathrm{~b}$ and 9c). thus, and in mode I (Fig. 9a), this superposition leads to a high instability of the matrix crack, defined by the strong values of the stress intensity factor. For this purpose, this stresses accumulation can lead to the initiation and propagation of fatigue cracks, may cause premature damage of MMC, at stresses well below the rupture threshold of this material.

As mentioned above, a crack initiated perpendicularly to the longitudinal axis of the fiber and subjected to tension stresses along this axis, propagates in pure opening mode. The crack propagates in modes II and III, results from the residual stresses alone (Fig. 9b and 9c). These results show that this mode (modes II and III) of rupture is preponderant only when the tip of this crack is localized, in the matrix or the fiber, very close to their interface (fiber-matrix interface).This behavior is all the more marked as the composite elaborated at high temperatures.

Our results clearly show that, the composites elaborated at high temperatures generate in the matrix and in the fiber, in the vicinity very close of their interface, a residual stress of high intensities. These stresses are the main causes of the matrix cracks instability, and especially when they are superimposed on commissioning stresses. This superposition is often responsible for the premature damage of the fibers, by the initiation and propagation of fatigue cracks. It is clear that, the fiber and the matrix are perfectly bonded only at too high temperatures. At these temperatures, the fiber-matrix bonds are too strong, and promote the charge transfer from the matrix to the fiber. Nevertheless, as our results show that, these temperatures weaken the composite by the introduction of residual stresses. This latter, can be partially relaxed by the interposition, between the matrix and the fiber, of an interphase whose thermal expansion coefficient of intermediate value between the two components of the composites.
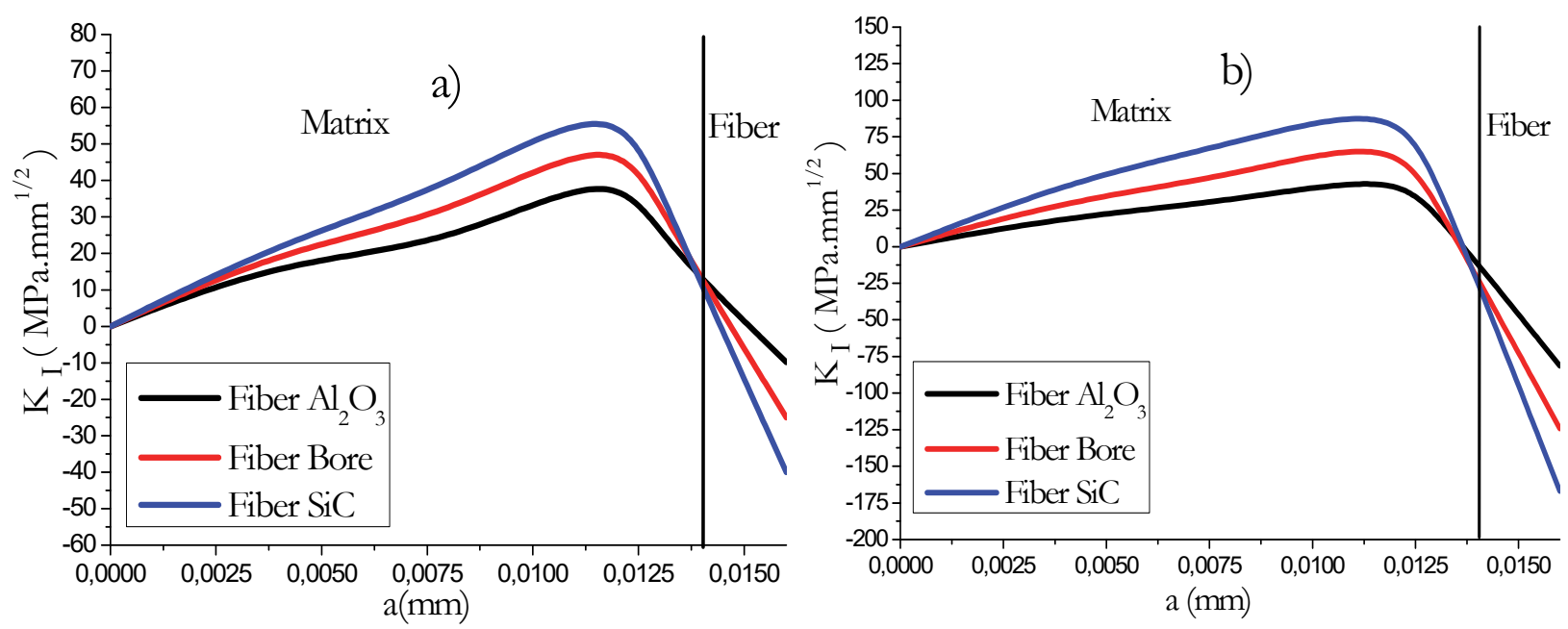

Figure 10: Variation of the stress intensity factor, in mode I according to the nature of the fiber and the intensity of the applied thermomechanical stresses. a) $\Delta \mathrm{T}=400^{\circ} \mathrm{C}, \sigma=120 \mathrm{MPa}$, b) $\Delta \mathrm{T}=800^{\circ} \mathrm{C}, \sigma=50 \mathrm{MPa}$.

\section{Effect of the nature of the matrix and the fiber}

As we have shown previously, the nature of the matrix and the fiber, defined in the thermomechanical loading by their Young's modulus and their thermal expansion coefficients, determine the level of the stresses originally mechanical and thermal. In this part, we analyze this nature effect on the matrix crack behavior as a function of the intensity of the applied thermomechanical stresses and the crack size (Fig. 10 and 11). The matrix chosen for this study is nickel. 
In mode I, in the matrix, the stress intensity factor increases with the decrease of the thermal expansion coefficients of the fiber and with the crack size (Fig.10a).Compared to this factor resulting from commissioning stresses and residual stresses originally thermal separately, this propagation parameter (SIF) resulting from the thermomechanical stresses is more important (Fig.10).

The comparative analysis of the results, illustrated in Figs. $10 \mathrm{a}$ and $10 \mathrm{~b}$, show that, in mode I, the crack is all the more unstable as the intensity of the applied thermomechanical stresses is greater. In the fiber, this type of stress leads to the stability of the crack by the closing of its lips.

The results in Fig. 11, shows the stress intensity factor variation in mode I as a function of the matrix nature reinforced by the Sic fiber and the intensity of the applied thermomechanical stresses.

In the matrix, this factor increases with the size of the crack (Fig. 11a) and the intensity of the applied thermomechanical stresses (Fig. 11b).
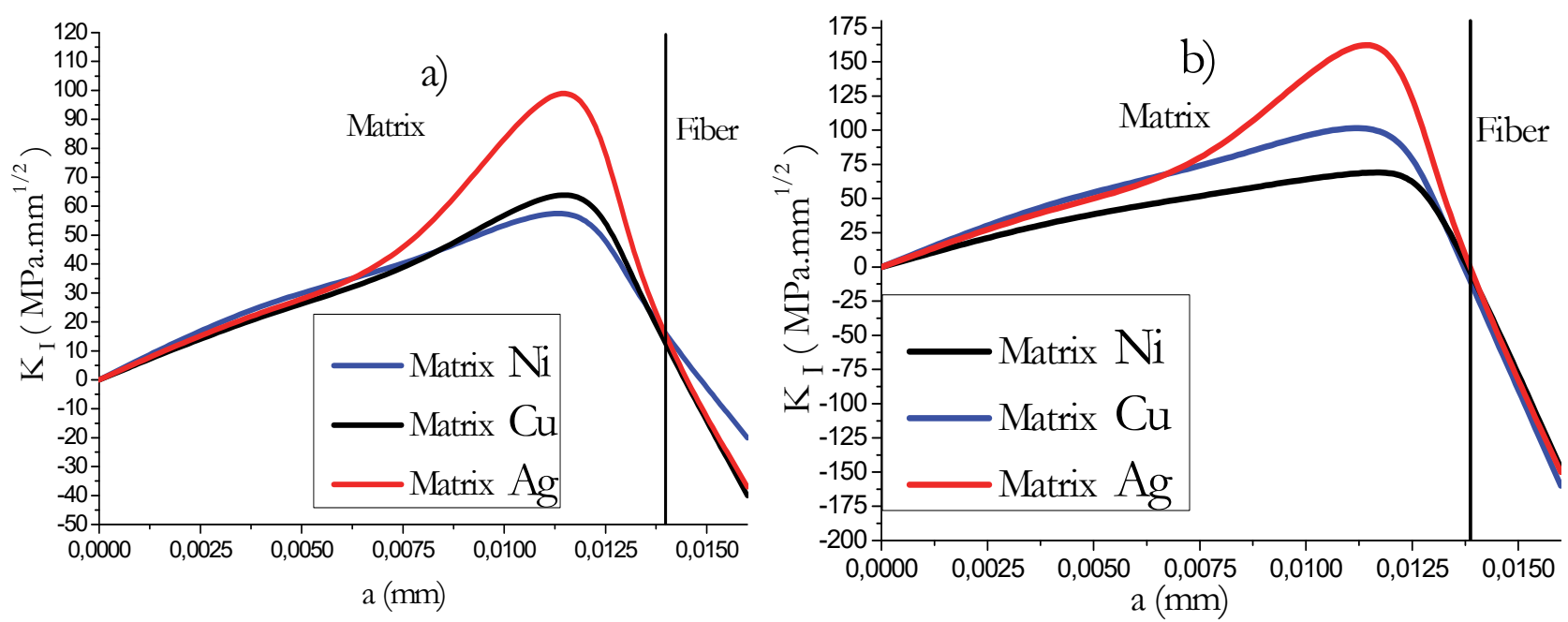

Figure 11: Variation of the stress intensity factor, in mode I according to the nature of the Matrix and the intensity of the applied thermomechanical stresses. a) $\Delta \mathrm{T}=400^{\circ} \mathrm{C}, \sigma=120 \mathrm{MPa}$, b) $\Delta \mathrm{T}=800^{\circ} \mathrm{C}, \sigma=50 \mathrm{MPa}$.

\section{CONCLUSION}

he results obtained in this study explicitly show that:

- Under the residual stress effect, a matrix crack propagates at the heart of the matrix in pure mode I, in the vicinity very close of the fiber-matrix interface in mixed modes I, II and III, and in the fiber in mixed shear modes II and III. The opening mode is the predominant mode. Residual stresses in the matrix are responsible for opening the crack lips (mode I), and compression in the fiber cause it to close;

- In mode I, the propagation kinetics of the matrix crack is all the stronger as the composite is elaborated at high temperatures. In the vicinity very close of the fiber-matrix interface, this propagation kinetics is slowed down. The lower values of the stress intensity factor are characteristic of this slowdown;

- Under the residual stress effect, a matrix crack, oriented, with respect to the axis of the fiber, propagates in the heart of the matrix and in the vicinity very close to the fiber-matrix interface, in mixed modes I, II and III. Such a crack crosses the fiber-matrix interface by shearing of its lips (modes II and III). The instability of the crack grows with the increase of the temperature of composite elaboration;

- Under the effect of tension commissioning stress of the composite, the matrix crack develops in pure mode I and penetrates the fiber by opening its lips. The propagation kinetics is strongly slowed down when its front approaches very close to the fiber-matrix interface and then grows rapidly in the fiber. This behavior is all the more accentuated as these stresses are more severe;

- Under the superposition action of the residual stresses to the commissioning stresses, the matrix crack propagates more quickly under the effect of these two stresses taken separately. The high stress intensity factor values in modes I, II and III are characteristic of this strong instability of the crack. The commissioning tension stresses add to the residual stresses in the matrix accelerates the propagation velocity of the crack in this matrix and makes this component vulnerable to damage 
by cracking. In the fiber, the commissioning tension stresses retract the residual stresses of compression and lead to the mode I closure of the crack. For this purpose, the crack propagates, in the matrix, in mixed modes I, II and III, the opening mode (mode I) is predominant, and in the fiber in shear modes II and III.

\section{REFERENCES}

[1] Hahn, Ch., A.M. Bourke, M. and R. Daymond, M. (2001). A finite-element analysis of the inelastic relaxation of thermal residual stress in continuous-fiber-reinforced composites. Composites Science and Technology, 61, pp. 17571772. DOI: 10.1016/S0266-3538(01)00075-6.

[2] Msallem, Y.A. (2008). Caractérisation thermique et mécanique d'un matériau composite aéronautique pendant le procédé d'élaboration : contribution à l'estimation des contraintes résiduelles. Thèse en partenariat avec Institut de recherche en génie civil et mécanique et de École centrale de Nantes.

[3] Sellam, S., Serier, B., Bouafia, F., Bachir Bouidjra, B. and Sardar, S. H. (2013). Analysis of the stresses intensity factor in alumina-Pyrex composites. Journal Computational Materials Science, 72, pp. 68-80.

DOI: $10.1016 /$ j.commatsci.2013.01.030

[4] Metehri, A., Serier, B., Bachir Bouiadjra, B., Belhouari, M. and Mecirdi M.A.(2009). Numerical analysis of the residual stresses in polymer matrix composites. Materials and Design Journal, 30, pp. 2332-2338. DOI: 10.1016/j.matdes.2008.11.009.

[5] Boutabout, B., Serier, B., Mecirdi, M.A. and Chama, M. (2008). Analyse numérique des contraintes résiduelles dans les bimatériaux céramique/métal. Revue des composites et des matériaux avancés, 18, pp.325-335. DOI:10.3166/rcma.18.325-335.

[6] Boutabout, B., Bouafia, F., Mecirdi, M A. and Bourdim S. M. (2010). Modélisation tridimensionnelle par éléments finis des contraintes résiduelles dans un composite à matrice en verre. Revue des composites et des matériaux avancés, 20, pp.7-23. DOI: $10.3166 / \mathrm{rcma} .20 .7-23$.

[7] Wang, H.W., Zhou, H.W., Ji, H.W. and Zhang, X.C. (2014). Application of extended finite element method in damage progress simulation of fiber reinforced composites. Journal Materials \& Design, 55, pp.191-196.

DOI: 10.1016/j.matdes.2013.09.071.

[8] Chi-Seung, L., Jeong-Hyeon, K., Seul-kee, K., Dong-Man, R. and Jae-Myung, L. (2015). Initial and progressive failure analyses for composite laminates using Puck failure criterion and damage-coupled finite element method. Journal Composite Structures, 121, pp.406-419. DOI: 10.1016/j.compstruct.2014.11.011.

[9] Wegglewski, W., Basista, M., Manescu, A., Chmielewski, M., Pietrzak, K. and Schubert, Th. (2014). Effect of grain size on thermal residual stresses and damage in sintered chromium-alumina composites: Measurement and modeling. Composites Part B: Engineering, 67, pp. 119-124. DOI: 10.1016/j.compositesb.2014.06.027.

[10] Prabha, M. and Srinivasan, M. S. (2014). A constituent-behavior-motivated model for damage in fiber reinforced composites. Computational Materials Science, 94, pp. 163-172. DOI: 10.1016/j.commatsci.2014.03.048.

[11]Jin, C.F., Zhu, Q.Z. and Shao J.F. (2014). A numerical analysis of interface damage effect on mechanical properties of composite materials. Mechanics Research Communications, 62, pp.18-24.

DOI: 10.1016/j.mechrescom.2014.08.003.

[12] Safarabadi, M. (2014). Understanding residual stresses in polymer matrix composites. In book: Residual Stresses in Composite Materials, pp. 197-232. DOI: 10.1533/9780857098597.2.197.

[13] Mecirdi, M.A. and Serier B. (2015). Calcul des facteurs d'intensité de contraintes (FIC) pour les fissures interfaciales dans les composites fibreux. Revue des composites et des matériaux avancés, 25, pp.311-325. DOI : $10.3166 / \mathrm{rcma} .25 .311-325$.

[14]Zeng,Yi., Xiong, X., Wang, D. and Liang W. (2015). Residual thermal stresses in carbon/carbon-Zr-Ti-C composites and their effects on the fracture behavior of composites with different performs. Carbon, 81, pp. 597-606. DOI: 10.1016/j.carbon.2014.09.094.

[15] Zhenyi, Y., Yongjun, W., Guigeng, Y., Aofe,i T., Zhenchao, Y., Shujuan, L., Yan, L. and Danlong, S.(2018). Evolution of curing residual stresses in composite using multi-scale method. Composites Part B: Engineering , 155, pp. 49-61. DOI: 10.1016/j.compositesb.2018.08.012.

[16] Nelson, S., Hanson, A., Briggs, T. and Werner B. (2018). Verification and validation of residual stresses in composite structures. Composite Structures, 194, pp. 662-673. DOI: 10.1016/j.compstruct.2018.04.017.

[17] Zhang, G., Wang, J., Ni, A. and Li, Sh. (2018). Process-induced residual stress of variable-stiffness composite laminates during cure. Composite Structures, 204, pp. 12-21. DOI: 10.1016/j.compstruct.2018.07.040. 
[18] Kati, R., Seyoung, K., Ji Haeng, Yu., Soo-Hyun, Kim., Young-Hoon, S. and In-Sub, H.(2018). Rietveld refinement and estimation of residual stress in GDC-LSCF oxygen transport membrane ceramic composites. Ceramics International, 44, pp. 10293-10298. DOI: 10.1016/j.ceramint.2018.03.036.

[19] Simulia, Dassault Systems. Abaqus software. Version 6.11. (2011).

[20] Serier, B. (1991). Eude et caractérisation des liaisons céramique-métal élaborées par thermocompression: Application au couple $\mathrm{Ag} / \mathrm{Al} 2 \mathrm{O} 3$.thèse de doctorat en Sciences. Génie des matériaux, Ecole Centrale de Lyon.

[21] Withers, Philip J. and Matthew, J. Roy. (2018). Residual Stresses in Metal Matrix Composites. In book: Reference Module in Materials Science and Materials Engineering Comprehensive Composite Materials II, 4, pp.275-286.

DOI: 10.1016/B978-0-12-803581-8.09963-X. 